\title{
Synthesis and Characterization of Gold Glyconanoparticles Functionalized with Sugars of Sweet Sorghum Syrup
}

\author{
C. Ganesh Kumar and Suman Kumar Mamidyala \\ Chemical Biology Laboratory, Indian Institute of Chemical Technology, Uppal Road, Hyderabad, Andhra Pradesh 500 607, India
}

\section{Bojja Sreedhar}

Inorganic and Physical Chemistry Division, Indian Institute of Chemical Technology, Uppal Road, Hyderabad, Andhra Pradesh 500 607, India

\section{Belum V. S. Reddy}

International Crops Research Institute for the Semi-Arid Tropics, Patancheru, Hyderabad, Andhra Pradesh 502 324, India

Gold glyconanoparticles were synthesized by a simple, rapid, and eco-friendly method by using sweet Sorghum syrup for application in biomedicine and biotechnology. The nanostructures of the prepared gold nanoparticles were confirmed by using $U V$-visible absorbance, TEM, SAED, FTIR, EDAX, XRD, and photoluminescence analyses. The formation of gold nanoparticles at both room and boiling temperatures and kinetics of the reaction were monitored by UV-visible spectroscopy and TEM studies. TEM analysis revealed that the obtained nanoparticles were mono-dispersed and spherical in shape with an average particle size of $7 \mathrm{~nm}$. The size of the nanoparticles was influenced by the concentration of Sorghum syrup. The presence of elemental gold was confirmed by EDAX analysis. Based on the FTIR analysis, it was observed that the sugars present in the Sorghum syrup possibly acts as capping agents. The zeta potential analysis revealed that the glyconanoparticles were negatively charged with a potential of $-25 \mathrm{mV}$. The XRD and SAED patterns also suggest that the nanoparticles were crystalline in nature and these particles were found to exhibit visible photoluminescence. Fructose and glucose present in sweet Sorghum syrup were demonstrated as responsible sugars for the reduction of gold ions, and sucrose stabilized the formed nanoparticles. The proposed mechanism for the formation and stabilization of gold glyconanoparticles is based on the phenomenon of "macromolecular crowding." This is the first report on the use of sweet Sorghum syrup for the green synthesis of gold glyconanoparticles at both room and boiling temperatures. (C) 2011 American Institute of Chemical Engineers Biotechnol. Prog., 27: 1455-1463, 2011

Keywords: gold glyconanoparticles, Sorghum syrup, fructose, glucose, nanotechnology

\section{Introduction}

In the past few decades, the area of nanotechnology has attracted a number of researchers with current emphasis on the development of nontoxic, clean and eco-friendly procedures that avoid the use of toxic chemicals in the preparative protocols. ${ }^{1}$ As a result, biological processes are appealing as possible environment-friendly nanofactories. Gold nanoparticles find a wide range of applications in catalysis, ${ }^{2}$ electroanalysis ${ }^{3,4}$ and as biosensors. ${ }^{5}$ In addition, gold nanoparticles find applications like detection of DNA and proteins, ${ }^{6,7}$ tumor directed drug delivery, ${ }^{8}$ hyperthermia agents for cancer treatment, ${ }^{9}$ contrast agents for biomedical imaging, ${ }^{10,11}$ $\mathrm{X}$-ray contrast agent, ${ }^{12}$ photothermal cancer therapy, ${ }^{13}$ and diagnostics. ${ }^{14-16}$ In all these applications, nanoparticles ex-

Additional Supporting Information may be found in the online version of this article.

Correspondence concerning this article should be addressed to C. G. Kumar atcgkumar@iict.res.in or at cgkumar1@rediffmail.com. hibit optical, electronic, magnetic, catalytic and/or scattering properties which are dependent on their size ${ }^{17}$ and shape. ${ }^{18}$ Two major challenges in the nanoparticle synthesis are: (a) to explore the novel synthetic routes that control over both the nanoparticle morphology and size, ${ }^{19,20}$ and (b) to characterize and understand the adsorption and structural configuration of the capping agents on the surface of nanoparticles, which is essential for predicting the nanoparticle stability. Considering these facts, efforts have been made by various researchers to use biological materials as capping agents to stabilize the nanoparticles. ${ }^{21}$ Sweet Sorghum [Sorghum bicolor (L.) Moench] is a high sugar-yielding crop that can be cultivated worldwide under diverse agro-climatic conditions with a requirement for a relatively less nitrogen rich fertilizer and water when compared to sugarcane and maize. It is a multipurpose biofuel feedstock that offers grain for human consumption, fodder for livestock and ethanol for transportation purposes. ${ }^{22}$ This crop has a $\mathrm{C}_{4}$ photosynthetic pathway, so it's photosynthetic rate and dry matter production is more or less similar to other crops like sugarcane and 
sugar beet. Furthermore, the sweet Sorghum stalks have the ability to accumulate high levels of sugars such as sucrose, glucose and fructose in the juice. ${ }^{23}$ The latter property is advantageous as the composition of sugars in honey was found suitable in the synthesis of gold nanoparticles. ${ }^{24}$

The aim of this study was to develop a simple and rapid green synthetic approach for the preparation of gold glyconanoparticles functionalized with sugars of sweet Sorghum syrup, which acted as stabilizer and capping ligands. Further, using different analytical techniques like UV-visible absorbance, TEM, SAED, FTIR, EDAX, XRD, and photoluminescence spectroscopy, the characterization of the prepared gold glyconanoparticles were investigated. To the best of our knowledge, this is the first report on the synthesis of gold glyconanoparticles using sweet Sorghum syrup at both room and boiling temperatures.

\section{Experimental}

\section{Materials and chemicals}

Sweet Sorghum syrup from cultivar CSH 22SS was procured from the decentralized sweet Sorghum crushing-cum-syrup making unit of the experimental farms located at Ibrahimabad village, Medak district of Andhra Pradesh, India. The syrup was collected into sterile sample bottles and then transported under cold ice-jacketed conditions to the laboratory for further experimental analysis. Gold (III) chloride hydrate $\left(\mathrm{HAuCl}_{4} \cdot 3 \mathrm{H}_{2} \mathrm{O}\right.$, analytical grade) was purchased from Sigma-Aldrich and used without further purification. All aqueous solutions were prepared in distilled deionized water.

\section{Preparation of gold nanoparticles}

Diluted sweet Sorghum syrup solution was prepared by dissolving $10 \mathrm{~g}$ of Sorghum syrup (of $60{ }^{\circ}$ Brix) in $100 \mathrm{~mL}$ of deionized water and used in further experiments. Different volumes of this diluted syrup solution $(0.25-1.5 \mathrm{~mL}$ with increment of $0.25 \mathrm{~mL}$ ) were added separately to $1 \mathrm{~mL}$ solutions of aqueous gold chloride $(1 \mathrm{mM})$ and the final volume was brought up to $10 \mathrm{~mL}$ by adding appropriate volume of deionized water. The reaction mixtures were allowed to stand for $2 \mathrm{~h}$ at room temperature, during which the reduction of $\mathrm{Au}^{+3}$ in all the reaction mixtures had reached saturation. UV-visible spectroscopy and transmission electron microscope (TEM) analyses were performed to evaluate the effect of different concentrations of diluted Sorghum syrup on the synthesis of gold nanoparticles and the prepared Au nanoparticles were characterized for their optical and nanostructural properties. Kinetics of the $\mathrm{Au}^{+3}$ reduction as a function of time was monitored for a particular optimized reaction (using $1.5 \mathrm{~mL}$ of Sorghum syrup solution) employing UV-visible spectroscopy. After the synthesis of gold nanoparticles, they were centrifuged at $12,000 \mathrm{rpm}$ for 10 min and the obtained pellet was subjected to dialysis to achieve isolation of nanoparticles that are free from proteins and other compounds present in the solution. Another set of same reaction mixtures as mentioned above, were boiled at $100^{\circ} \mathrm{C}$ for $10 \mathrm{~min}$ to evaluate the effect of boiling on nanoparticle synthesis and the quality of gold glyconanoparticles formed. A control reaction mixture at room temperature was also run in parallel. These reaction mixtures were further analyzed using UV-visible spectroscopy and TEM studies. The dried powder of gold nanoparticles was obtained by lyophilization and stored in a vacuum desiccator at room tempera- ture. To monitor the stability of glyconanoparticles, the stored particles were redispersed in water by sonication to regenerate a sol followed by UV-visible spectroscopic analysis on different days.

\section{Characterization of gold nanoparticles}

The optical properties of the gold nanoparticles dispersed in water were monitored on a Perkin-Elmer Lambda 25 UV-visible double beam spectrophotometer. Morphological analysis of gold nanoparticle formation was confirmed using a TEM. Samples for TEM analysis were prepared by drying a dispersion of the nanoparticles on amorphous carbon-coated copper grids. Gold nanoparticles were imaged using a Philips Technai-FE 12 TEM instrument operated at an accelerating voltage at $120 \mathrm{kV}$. The dialyzed nanoparticles were dried to obtain a powder which was subjected to further FTIR analysis. The FTIR spectrum of gold nanoparticles in the form of $\mathrm{KBr}$ pellets was recorded on a Thermo-Nicolet Nexus 670 spectrophotometer at $4 \mathrm{~cm} \mathrm{sec}^{-1}$ resolution in wavenumber region of $400-4,000 \mathrm{~cm}^{-1}$. The energy-dispersive X-ray (EDAX) spectroscopy was analyzed with an EDAX detector (Oxford LINK-ISIS 300) equipped on a scanning electron microscope (SEM, Hitachi S-520) operated at an accelerating voltage of $10 \mathrm{kV}$. The X-ray diffraction (XRD) measurements of the gold nanoparticles was carried out on a MAXima_X XRD-7000 (Shimadzu, Japan) diffractometer operating at a voltage of 40 $\mathrm{kV}$ and a current of $30 \mathrm{~mA}$ with $\mathrm{Cu} \mathrm{K}_{\alpha}$ radiation in the scan range $2 \theta=10-75^{\circ}$. The photoluminescence (PL) spectrum of the gold nanoparticles dispersed in water and their appropriate controls of Sorghum syrup excluding $\mathrm{HAuCl}_{4}$ was measured using Infinite M200 (Tecan Group, Switzerland) spectrophotometer with samples placed in a nonfluorescent quartz cuvette. An excitation wavelength of $300 \mathrm{~nm}$ was used. The gold nanoparticle charge quantified as zeta potential was determined using a Zetasizer Nano ZS (Malvern Instruments, Worcestershire, UK). Measurements were performed in distilled water at $25^{\circ} \mathrm{C}$.

\section{Sugar composition analysis of sweet Sorghum syrup and to identify the role of the respective sugars for reduction and capping of gold ions}

The relative percentages of hexose sugars like glucose, fructose, and sucrose present in the sweet Sorghum syrup of cultivar CSH 22SS were analyzed on a Shimadzu HPLC system (Kyoto, Japan) interfaced by Shimadzu RID-10A refractive index detector (Kyoto, Japan). The HPLC was equipped with a Phenomenex Luna $\mathrm{NH}_{2}$ 100R column $(250 \times 4.6$ $\mathrm{mm}, 5 \mu \mathrm{m}$ particle size, Aschaffenburg, Germany). The chromatographic mobile phase composed of acetonitrile-water $(80: 20, \mathrm{v} / \mathrm{v})$ was run at a flow rate of $1.0 \mathrm{~mL} \mathrm{~min}^{-1}$ in isocratic mode with column temperature maintained at $40^{\circ} \mathrm{C}$. Standard stock solution $\left(1,000 \mu \mathrm{g} \mathrm{mL} \mathrm{m}^{-1}\right)$ of different sugars was prepared in Milli-Q water as a diluent for analysis. After stabilizing the HPLC system, standard sugar solution was injected and using operating parameters a standard calibration was prepared for checking the reproducibility of the chromatograms. Different parameters like retention time, component concentration, peak area of each component were used for calculating the content of respective sugars. The chromatographic and integrated data were recorded using HP-Vectra (Hewlett Packard, Waldron, Germany) computer system interfaced to LC-20 AD data acquiring software for 

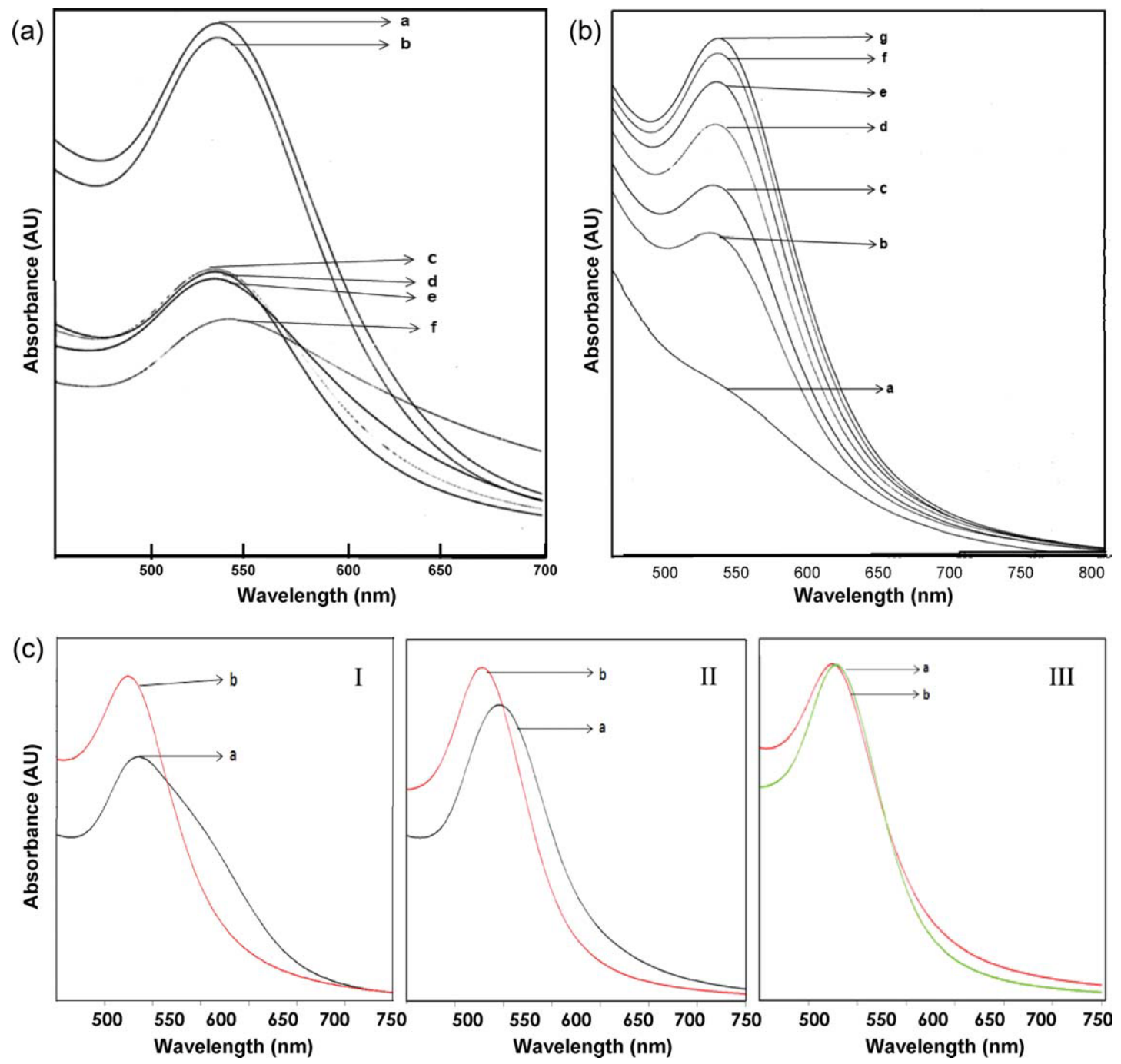

Figure 1. UV-visible spectrum of gold glyconanoparticles synthesis using (A) $1 \mathrm{mM}$ aqueous gold chloride (1 $\mathrm{mL})$ recorded as a function of different concentrations of diluted Sorghum syrup solution (curves a - f corresponds to $1.5,1.25,1.0,0.75,0.5$, and $0.25 \mathrm{~mL}$ of diluted Sorghum syrup solution) (B) Diluted Sorghum syrup $(1.5 \mathrm{~mL})$ recorded as a function of reaction time (curves a - g corresponds to $0,3,6,9,12,15$, and $18 \mathrm{~min}$ of the reaction) (C) At room temperature (curve a) and at boiling temperature (curve b) conditions using diluted Sorghum syrup solution: (I) $0.25 \mathrm{~mL}$, (II) $0.75 \mathrm{~mL}$, and (III) $1.5 \mathrm{~mL}$.

data management. The concentration of each sugar in the syrup was determined from peak area of the chromatograms and expressed in terms of percentage of total sugars. ${ }^{25}$

The role of the possible sugars responsible for the reduction of gold ions were evaluated by setting up separate reactions for nanoparticle preparation using respective concentration of each sugar individually with $1 \mathrm{~mL}$ of aqueous gold chloride solution and the final volume was brought up to $10 \mathrm{~mL}$ by adding appropriate volume of deionized water. The reaction mixtures were allowed to stand for $2 \mathrm{~h}$ at room temperature. Similarly, the reactions were also carried out using a combination of glucose and fructose and a combination of glucose, fructose and sucrose to verify the role of these respective sugar combinations. The effect of these sugars on the morphology of gold nanoparticle formation was further confirmed by TEM studies.

\section{Results and Discussion}

\section{$U V$-visible spectral analysis}

The diluted sweet Sorghum syrup solution reduced the $\mathrm{Au}^{3+}$ ions at room temperature resulting in the formation of purple colour which indicated the synthesis of gold glyconanoparticles. The reduction of $\mathrm{Au}^{3+}$ ions after a reaction period of $2 \mathrm{~h}$ was monitored by $\mathrm{UV}$-visible spectroscopy and the spectrum of gold glyconanoparticles was recorded as a function of different concentrations of Sorghum syrup solution with gold chloride (Figure 1a). UV-visible spectra of gold glyconanoparticles obtained at different concentrations of Sorghum syrup clearly revealed significant changes in the spectrum (Figure 1a), which was distinguished by a broad surface plasmon resonance (SPR) peak at about $540 \mathrm{~nm}$ at lower concentrations and an absorption band at $530 \mathrm{~nm}$ was observed in the blue shift region at higher concentrations, which may be due to the reduction in the size of nanoparticles. In general, the localized SPRs are generated due to the collective oscillations of conductive electrons from the sample species. The appearance of strong SPR peaks obtained from the excitation of localized SPR is due to the absorption of light at a specific wavelength. ${ }^{26}$ The optical absorption spectrum of metal nanoparticles is dominated by the SPR leading to a distinguished red or blue shift depending on the dielectric properties of the surrounding host matrix or the environment atmosphere, in addition to particle 


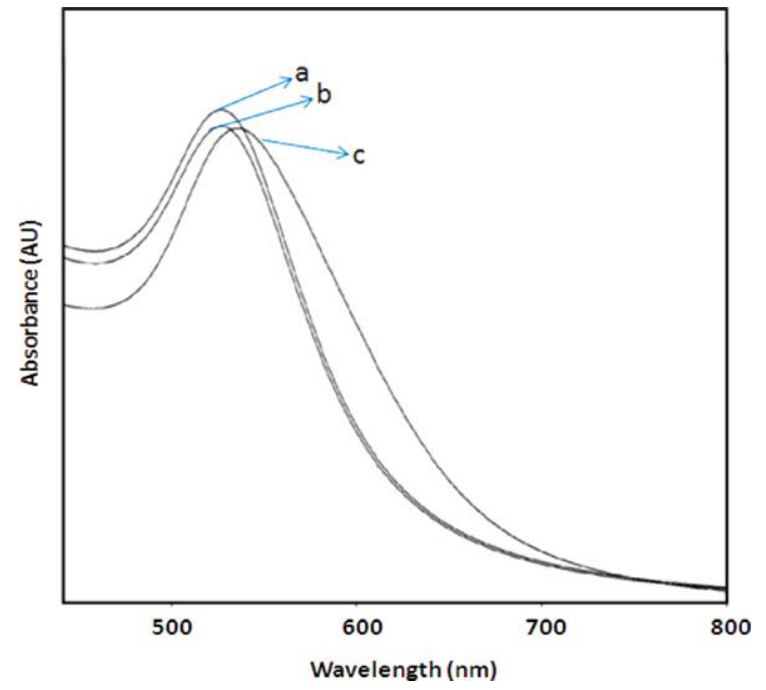

Figure 2. UV-visible spectrum of gold glyconanoparticles dispersed in water at room temperature recorded after (a) 1, (b) 30, and (c) 35 days for stability assessment.

size and shape. ${ }^{20}$ The absorption band observed at $530 \mathrm{~nm}$ is the characteristic SPR of spherical gold glyconanoparticles. ${ }^{27}$ At lower concentrations of Sorghum syrup, a broad SPR peak was observed and the sharpness as well as intensity of the resonance band increased with respect to the increase in the concentration of Sorghum syrup solution (Figure 1A). The plausible reason may be the insufficient reductants which may result in a partly aggregated state at lower concentrations and at higher concentrations more nanoparticles were formed due to the complete reduction and the formed nanoparticles were better dispersed due to the protection from agglomeration. The spherical gold nanoparticles of variable sizes are known to exhibit absorption in the range of 520-550 nm. ${ }^{19}$ The time course of the reaction for a particular optimized concentration $(1.5 \mathrm{~mL})$ of Sorghum syrup was monitored by UV-visible spectroscopy and the obtained spectrum is represented in Figure 1B. A strong resonance peak centered at about $530 \mathrm{~nm}$ was clearly seen and increased in its intensity as a function of time, and it was stabilized after $18 \mathrm{~min}$. It is well established that the optical properties of gold nanoparticles are influenced by size and shape. ${ }^{28}$ All the reaction mixtures on boiling turned to cherry red in color within 10 min suggesting that the reduction of $\mathrm{Au}^{+3}$ ions was 10 times more faster at boiling temperature as compared to room temperature conditions. This is due to the fact that under the experimental conditions the formation of acid results in the hydrolysis of sucrose to glucose and fructose. The UV-visible spectroscopic analysis (Figure 1C), clearly indicate a blue shift in SPR band from $540 \mathrm{~nm}$ to $530 \mathrm{~nm}$ at lower Sorghum syrup concentrations of $0.25 \mathrm{~mL}$ (I) and $0.75 \mathrm{~mL}$ (II), respectively; but no significant difference was observed at higher concentrations of $1.5 \mathrm{~mL}$ (III).

The stability of glyconanoparticles was evaluated by UVvisible spectroscopy and the respective absorption spectra are shown in Figure 2. After day 1, the nanoparticles showed an intense absorption peak around $530 \mathrm{~nm}$. As the time progressed from 1 to 30 days, similar plasmon resonance bands were observed with no change in the position of SPR, except for a decrease in the absorption intensity. At 35th day, a shift in the position of SPR was observed with a decrease in intensity, suggesting that the stability of nanoparticles decreased after 30 days.

\section{TEM and SAED analysis}

Transmission electron microscope (TEM) micrographs are shown in Figures $3 \mathrm{a}-\mathrm{c}$, which demonstrates clearly the formation of gold nanoparticles synthesized using different concentrations of Sorghum syrup solution at room temperature. Figure 3 a corresponds to the TEM micrograph of gold nanoparticles prepared using $0.25 \mathrm{~mL}$ of Sorghum syrup solution. The TEM analysis clearly revealed the formation of spherical nanoparticles, but few of them were found to be irregular in shape, which might be due to the aggregation of nanoparticles. The size distribution histogram plot constructed from the TEM micrograph is shown in Figure $3 b$. The diameter of these nanoparticles ranged from 18 to $30 \mathrm{~nm}$ with an average particle size of $25.5 \mathrm{~nm}(\sigma=3.5 \mathrm{~nm})$. The TEM picture for the gold nanoparticles obtained with $0.75 \mathrm{~mL}$ of Sorghum syrup solution and the corresponding particle size distribution histogram (on the right hand side) is represented in Figure $3 \mathrm{~b}$. The particles are predominantly spherical in shape and nonagglomerated. These particles were in a size range of 6-15 nm with an average particle size of $11.5 \mathrm{~nm}(\sigma=2.3 \mathrm{~nm})$. The average particle size of these nanoparticles is less than those obtained using $0.25 \mathrm{~mL}$ of Sorghum syrup solution.

The TEM picture of gold nanoparticles synthesized using $1.5 \mathrm{~mL}$ of Sorghum syrup solution and the corresponding size distribution histogram (on the right hand side) constructed from TEM image is shown in Figure 3c. These nanoparticles observed were mono-dispersed and spherical in shape embedded in a matrix of Sorghum syrup. The gold nanoparticles formed were in the size range of 3-15 nm with an average particle size of $7 \mathrm{~nm}(\sigma=1.6 \mathrm{~nm})$ with narrow size distribution. These results are in fine tuning with the observed optical properties of gold nanoparticles. These results also clearly suggest that as the concentration of Sorghum syrup in the reaction mixture increased gradually, the average size of the nanoparticles decreased significantly. This might be due to prevention in the aggregation of nanoparticles due to effective stabilization by the Sorghum syrup solution at higher concentrations. The typical selected area electron diffraction (SAED) pattern (inset in Figure 3c) shows bright circular rings which corresponds to the (111), (200), (220), and (311) planes, suggesting that the synthesized gold nanoparticles were highly crystalline.

The TEM micrographs of gold glyconanoparticles obtained at boiling temperature with $0.25 \mathrm{~mL}$ (I) and $0.75 \mathrm{~mL}$ (II) of Sorghum syrup are shown in Figure 4. The TEM analysis clearly indicates the formation of fairly spherical gold nanoparticles of well dispersed nature with average particle sizes of $11 \mathrm{~nm}(0.25 \mathrm{~mL}$ concentration) and $9.5 \mathrm{~nm}(0.75 \mathrm{~mL}$ concentration), and the dispersion increased at lower concentrations of Sorghum syrup at $100^{\circ} \mathrm{C}$ as compared to control reaction mixtures at room temperature. At higher syrup concentrations, there was no significant difference observed. These results clearly suggest that the quality of the gold glyconanoparticles and rate of the reduction of gold ions at higher temperature increased tremendously which is due to the enhanced reducing efficiency of the reducing sugars at elevated temperatures. It was earlier established that the reducing efficiency is more for reducing sugars at higher temperatures as compared to lower temperatures. $^{29}$

\section{FTIR, EDAX, and zeta potential analysis}

Fourier transform infrared (FTIR) and Energy dispersive $\mathrm{X}$-ray (EDAX) studies were carried out to evaluate the 

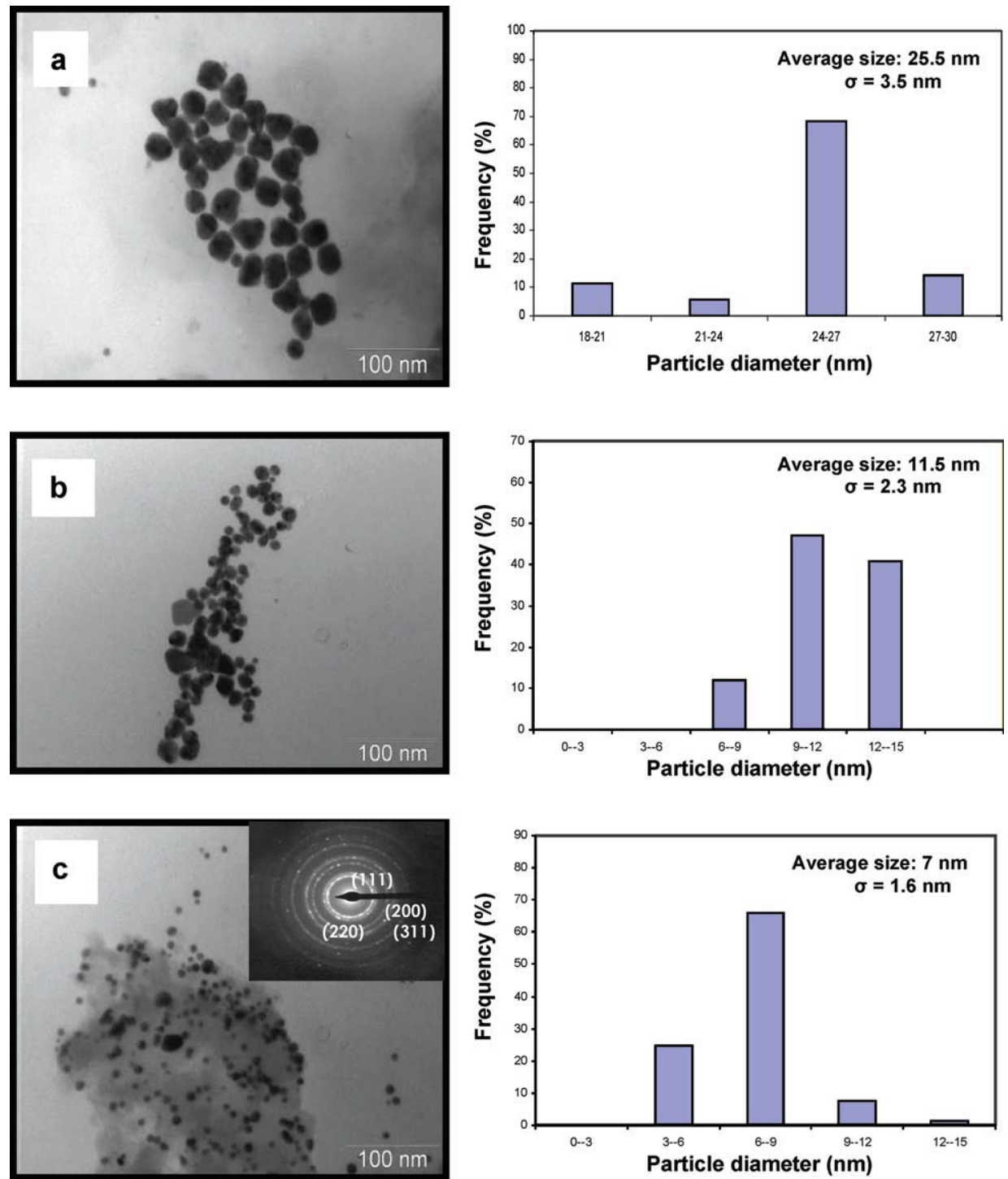

Figure 3. Transmission electron micrographs and corresponding particle size distribution histograms (on the right hand side) of gold glyconanoparticles prepared at room temperature using different concentrations of diluted Sorghum syrup solution: (a) 0.25 wt $\%$, (b) 0.75 wt $\%$, and (c) 1.5 wt \%.

Inset: Selected area electron diffraction (SAED) pattern of gold nanoparticles.

possible biomolecules responsible for capping and stabilization of gold nanoparticles synthesized by Sorghum syrup solution. The FTIR spectrum of gold nanoparticles (Figure 5a) showed the presence of bands at 3,420, 2,924, 2,855, 1,628, and $1,056 \mathrm{~cm}^{-1}$. The bands at 3,420 and $1,628 \mathrm{~cm}^{-1}$ are due to hydroxyl and carbonyl stretch vibrations in the sugars present in the Sorghum syrup. The bands at 2,924 and 2,855 $\mathrm{cm}^{-1}$ may arise due to the stretching vibrations of $\mathrm{C}-\mathrm{H}$ groups of sugars. A band of $\mathrm{C}-\mathrm{O}$ and $\mathrm{C}-\mathrm{C}$ stretching vibrations in sugars was observed at $1,056 \mathrm{~cm}^{-1} \cdot{ }^{30}$ In comparison to the FTIR spectrum of Sorghum syrup solution (Figure $5 b$ ), it is clearly observed that the absorption bands of gold nanoparticles were prominent with an increase in the wavenumbers and this could be due to the coordination bonds between gold nanoparticles and functional groups (hydroxyl and carbonyl groups) of sugar molecules (capping ligands) of Sorghum syrup solution.

As these sugars bear multiple hydroxyl groups and few of them may be engaged in the binding to nanoparticles. The EDAX spectrum (Figure 6) recorded for the synthesized gold nanoparticles showed a strong Au signal near at $2 \mathrm{keV}$. The EDAX spectrum also suggests the presence of $\mathrm{C}$ and $\mathrm{O}$ elemental peaks which may originate from the biomolecules that are bound to surface of gold nanoparticles. The FTIR and EDAX spectroscopic studies strongly suggest that the gold nanoparticles are possibly functionalized by the sugars (i.e., glucose and/or fructose) present in the syrup and are stabilized by these biomolecules. The zeta potential (Supporting Information Figure S1) indicates the overall charge that a nanoparticle acquires in a particular medium and a zeta potential of $-25 \mathrm{mV}$ was measured for the synthesized gold glyconanoparticles suggesting an anionic charge on the nanoparticle surface which may be due to surface bounded sugar moieties and the result supports the FTIR and EDAX analysis.

\section{XRD analysis}

The X-ray diffraction (XRD) pattern (Supporting Information Figure S2) of gold glyconanoparticles prepared using 


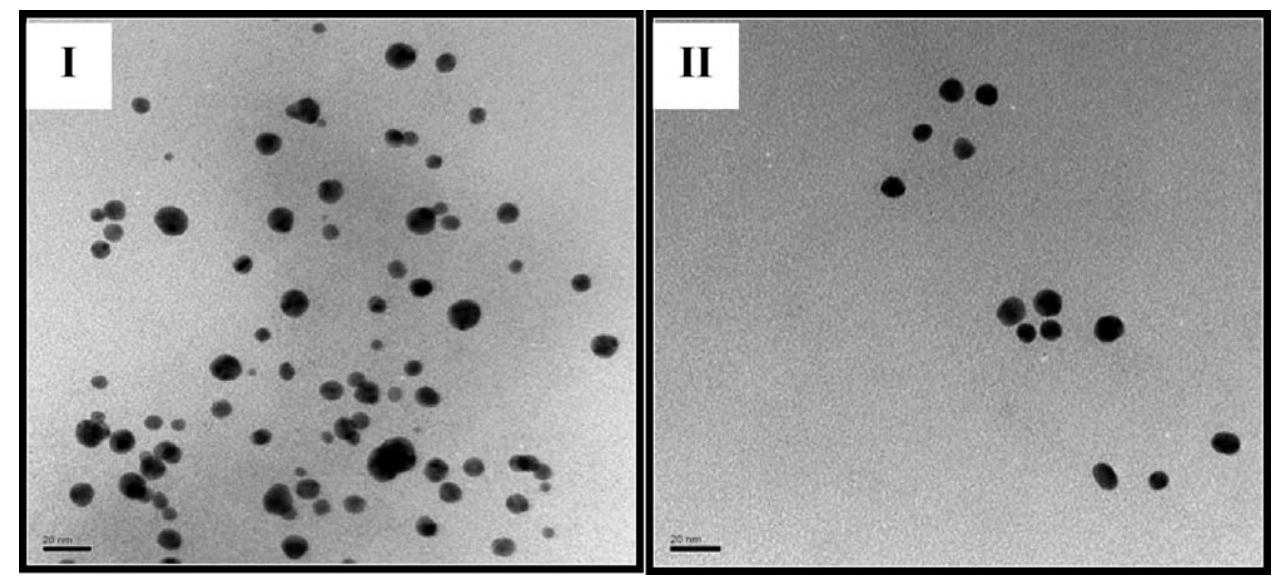

Figure 4. Transmission electron micrographs of gold glyconanoparticles synthesized at boiling temperature using diluted Sorghum syrup solution: (I) $0.25 \mathrm{~mL}$ and (II) $0.75 \mathrm{~mL}$.

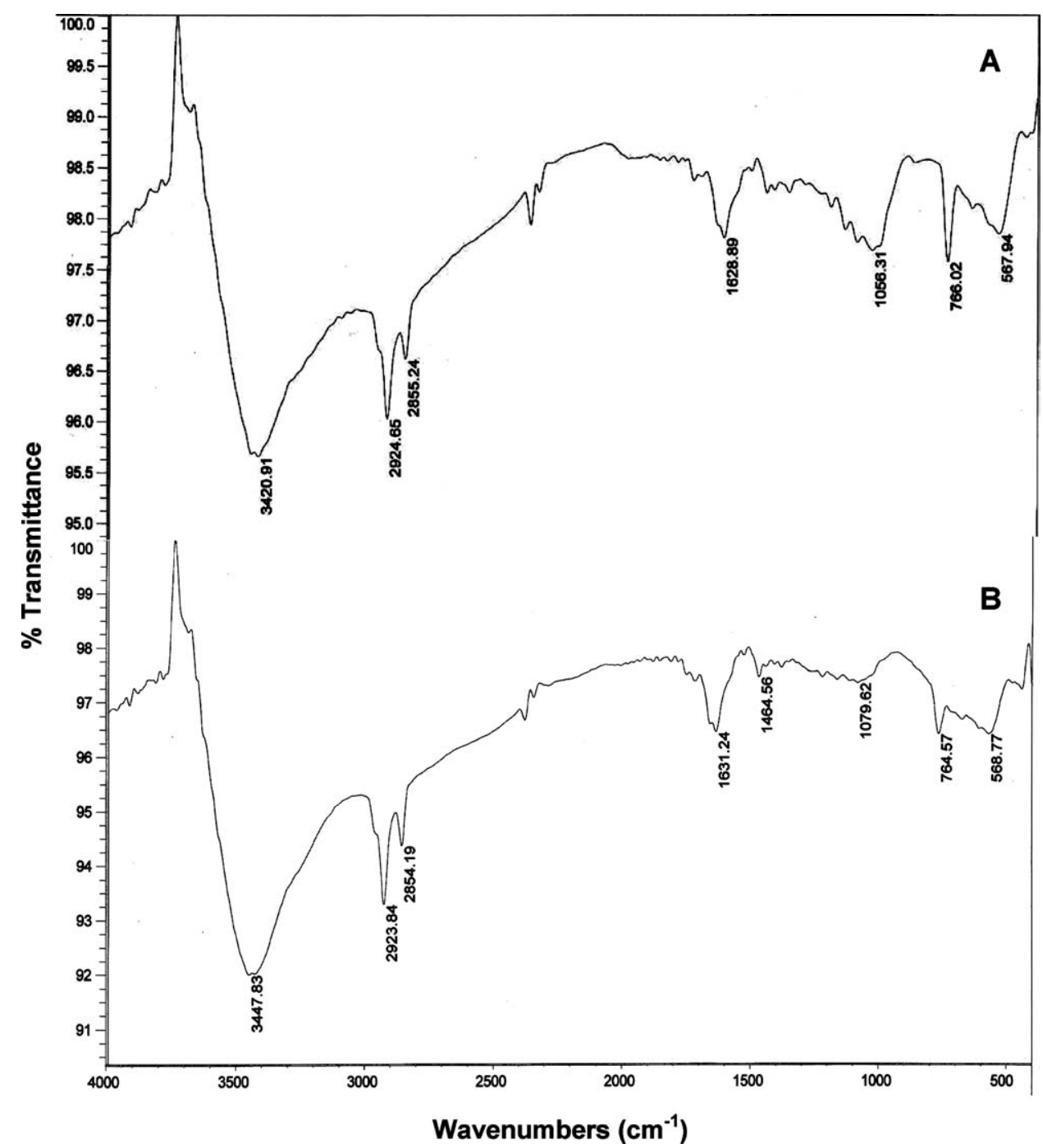

Figure 5. FTIR spectrum of (a) gold glyconanoparticles capped with sweet Sorghum syrup sugars, and (b) sweet Sorghum syrup solution.

sweet Sorghum syrup solution exhibits the characteristic Bragg diffraction peaks due to gold nanocrystallites. The prominent Bragg reflections observed at $2 \theta$ values of 38.2, 44.4, and 64.6 corresponds to (111), (200), and (220) facets of the face centered cubic (fcc) gold nanoparticles. ${ }^{24}$ The XRD results suggest that the prepared the gold glyconanoparticles are crystalline. 


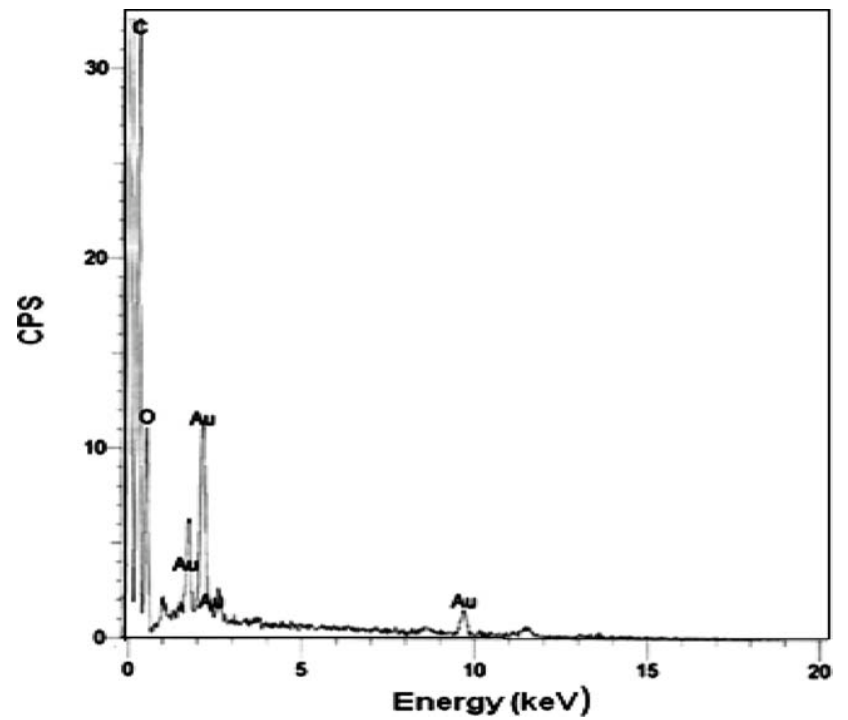

Figure 6. Energy dispersive X-ray (EDAX) spectrum of gold glyconanoparticles.

\section{Photoluminescence study}

Photoluminescence spectroscopy is a simple and versatile nondestructive tool for the electrical characterization of surfaces and interfaces, and the photoluminescence measurements explore the electronic features of the sample directly. The photoluminescence spectrum of the gold nanoparticles obtained using different concentrations of sweet Sorghum syrup solution along with respective controls is showed in Figure 7. The spectra recorded at an excitation wavelength of $300 \mathrm{~nm}$ and photoluminescence intensity was observed at $430 \mathrm{~nm}$, which is due to the surface functionalization of gold nanoparticles with biomolecules present in sweet Sorghum syrup. The photoluminescence intensity increased gradually from lower to higher concentrations of sweet Sorghum syrup. It was also demonstrated that parallel controls of native sweet Sorghum syrup without $\mathrm{HAuCl}_{4}$ also exhibited photoluminescence. However, the photoluminescence intensity of the test samples was higher as compared to the respective controls. It is well established that nano-sized metals like silver and gold exhibit visible photoluminescence due to inter band transitions ( $\mathrm{d}$ to $\mathrm{sp}$ ). ${ }^{31}$ Another possibility may be due to the residual $\mathrm{Au}$ (I) which might be present in the nanoparticle may gives rise to fluorescence, especially if the Au (III) to $\mathrm{Au}(0)$ reduction is not complete, or the fluorescence could arise from the oxidized products of sweet Sorghum syrup. This property suggests that these nanoparticles could find use in therapeutic applications. ${ }^{24}$

\section{Identification of possible sugars present in sweet Sorghum syrup responsible for reduction and capping of gold ions}

Nanoparticles capped with sugar molecules as ligands are termed as glyconanoparticles. Much of the recent research efforts have focused on the synthesis of gold and silver glyconanoparticles functionalized with different sugars like monosaccharide, ${ }^{32}$ disaccharide, ${ }^{33} \mathrm{Le}^{\mathrm{y}}$ tetrasaccharide ${ }^{34}$ and rhamnolipid. $^{35}$ (Kumar et al. 2010) In addition, some reports exist on glyco-quantum dots ${ }^{36}$ and magnetic glyconanoparticles. $^{37}$ The carbohydrates contain many hydroxyl and carbonyl groups which confer the glyconanoparticles with unique H-bonding capabilities for building smart nanomaterials. These glyconanoparticles find application in biomedicine

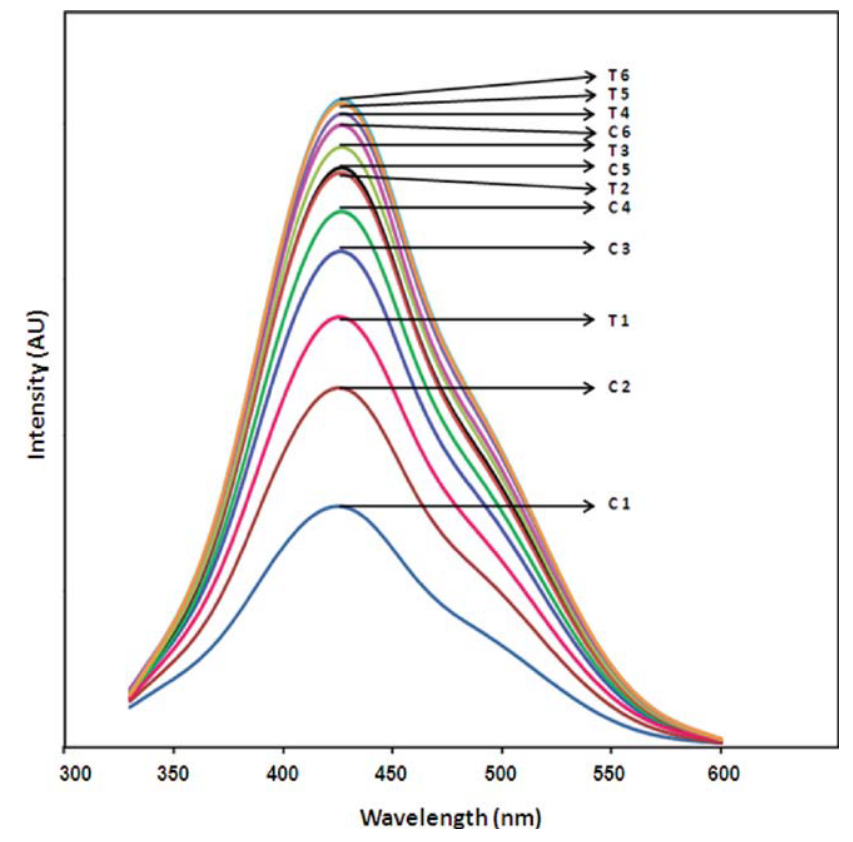

Figure 7. Photoluminescence spectrum of gold glyconanoparticles prepared using different concentrations of sweet Sorghum syrup solution, i.e., 0.25, 0.5, 0.75, 1.0, 1.25, $1.5 \mathrm{~mL}$, represented as curves T1-T6 and respective controls represented as curves $\mathrm{C1}-\mathrm{C} 6$.

as probes of carbohydrate-carbohydrate interactions and carbohydrate-protein interactions, antiadhesive therapy, biolabels, bioamplification strategies, and in material science for microstructure manipulation, quantum dots and magnetic bioconjugation. ${ }^{38}$ The relative percentages of sugars quantified in sweet Sorghum syrup of cultivar CSH 22SS by HPLC analysis were $20 \%, 15 \%$, and $65 \%$ for glucose, fructose and sucrose, respectively. The gold nanoparticle formation was observed only in reaction mixtures containing reducing sugars like glucose and fructose. Further, the reaction was carried out by using a combination of glucose and fructose, which resulted in the formation of gold nanoparticles more rapidly. The rate of nanoparticle formation was found to be greater for fructose in combination with glucose followed by fructose and glucose individually. These findings suggest that fructose and glucose are responsible for the reduction of gold ions. The TEM images of gold glyconanoparticles prepared by individual sugars and with combination of sugars are shown in Figure 8. The nanoparticles synthesized using glucose (Figure $8 \mathrm{a}$ ) and fructose (Figure $8 \mathrm{~b}$ ) were observed to have different shapes, i.e. triangles, hexagonal and the remaining were irregular in shape and in an aggregated form. A combination of glucose and fructose (Figure 8c) yielded irregular spherical shaped nanoparticles and they were of larger size. The combination of sucrose, glucose and fructose (Figure 8d) yielded fairly spherical shaped nanoparticles with lower percentage of agglomeration. These results indicated that the presence of sucrose greatly influenced the size and shape of the nanoparticles and sucrose was identified to play a key role in the stabilization of nanoparticle formation. It was also reported in an earlier study that commonly available simple sugars like glucose and fructose assisted in the synthesis of stable gold nanoparticles by a wet chemical method and fructose was found to be the suitable sugar. ${ }^{29}$

The proposed mechanism illustrated in Figure 9 for the formation and stabilization of the gold glyconanoparticles is 


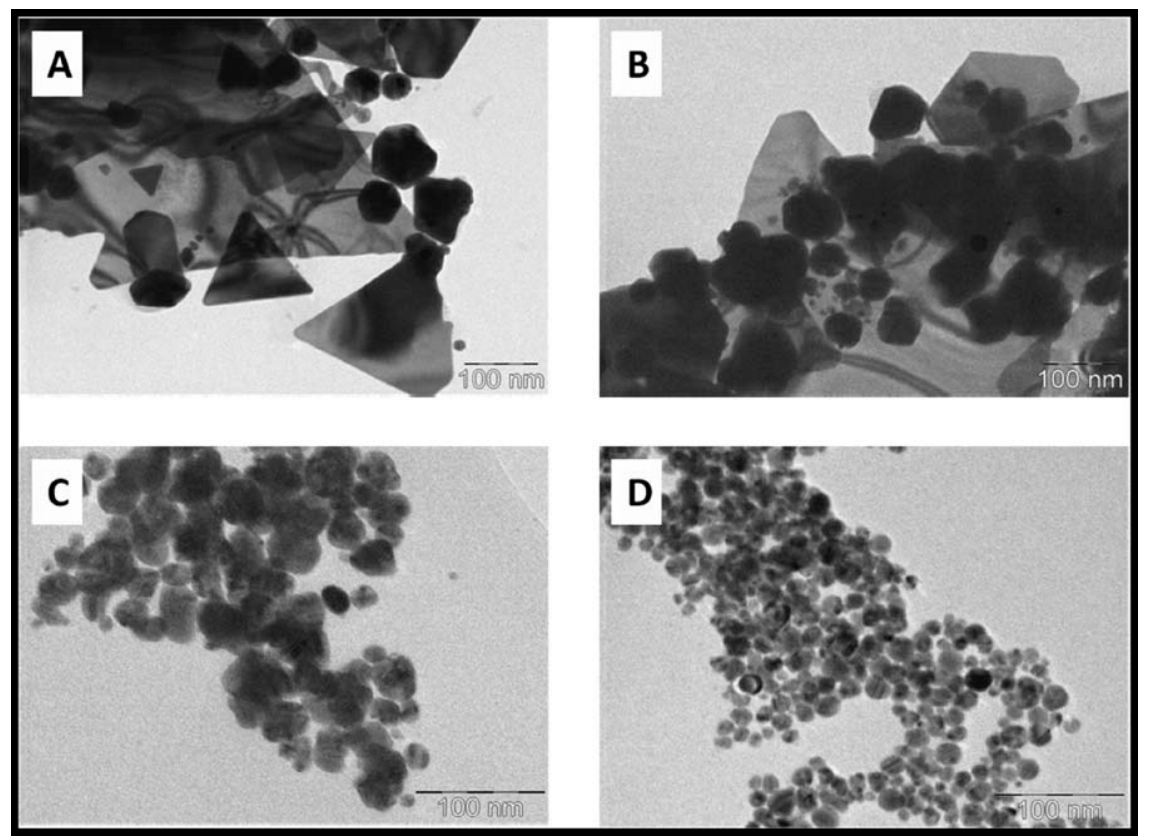

Figure 8. Transmission electron micrographs of gold glyconanoparticles prepared using individual sugars: (a) Glucose, (b) Fructose, and in combinations: (c) Glucose + Fructose, and (d) Glucose + Fructose + Sucrose.

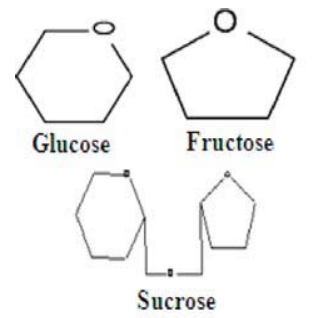

Sorghum syrup

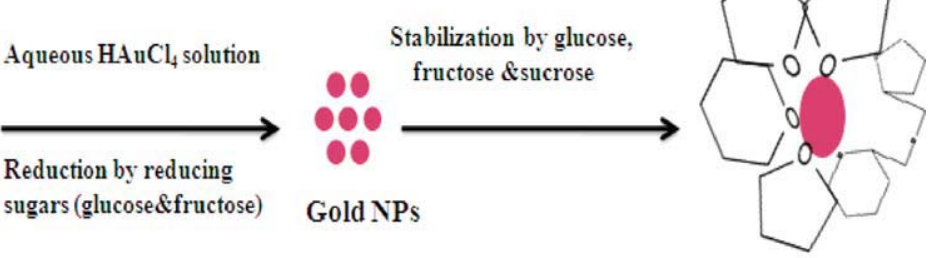

Sugar(s) capped gold NPs

Figure 9. Schematic representation of the proposed mechanism for formation and stabilization of gold glyconanoparticles.

based on the phenomenon of macromolecular crowding, which prevents the nanoparticles from aggregation. In cell biology, the term macromolecular crowding refers to the conditions where molecules occupy $40 \%$ of the physical volume and this phenomenon has been demonstrated to affect many molecular and physical processes. ${ }^{39}$ Similarly in the present study, the sugars present in the sweet Sorghum syrup occupy $\sim 40 \%$ of the total aqueous volume, which imposes a physical constraint that secludes the nanoparticles from each other, thus preventing the aggregation.

\section{Conclusions}

The present study demonstrates for the first time the use of sweet Sorghum syrup in the rapid synthesis of stable gold glyconanoparticles at room temperature. The process is facile, easy, reproducible and does not use any surfactants. UVvisible spectroscopy was used to monitor the kinetics of nanoparticle formation. The formed nanoparticles are mostly spherical in shape with an average particle size of $7 \mathrm{~nm}$, which is confirmed by TEM images and XRD analysis. Sweet Sorghum syrup contains glucose and fructose which are responsible for the reduction of gold ions and acted as capping agents along with sucrose leading to the formation and stabilization of gold glyconanoparticles, which is confirmed by FTIR studies. Further, the glyconanoparticles synthesized by this method were quite stable and remained intact without the deterioration of particle morphology for 1 month under room temperature conditions in a vacuum desiccator.

\section{Acknowledgment}

The authors acknowledge the financial assistance provided in the form of a Senior Research Fellowship by the Council of Scientific and Industrial Research (CSIR), New Delhi, Government of India to Mr. S. K. Mamidyala. The authors also wish to thank Prof. V. Lakshmipati for his valuable suggestions and comments during the preparation of the manuscript.

\section{Literature Cited}

1. Mallikarjuna NN, Varma RS. Microwave assisted shape controlled bulk synthesis of noble nanocrystals and their catalytic properties. Cryst Growth Des. 2007;7:686-690.

2. Cortie MB, van der Lingen E. Catalytic gold nanoparticles. Mat Forum. 2002;26:1-14.

3. Raj CR, Okajima T, Ohsaka T. Gold nanoparticle arrays for the voltammetric sensing of dopamine. $J$ Electroanal Chem. 2003;543:127-133

4. Zhang L, Jiang XE, Wang EK, Dong SJ. Attachment of gold nanoparticles to glassy carbon electrode and its application for the direct electrochemistry and electrocatalytic behavior of hemoglobia. Biosens Bioelectron. 2005;21:337-345. 
5. Sanz VC, Mena ML, Gonzalez-Cortes A, Yanez-Sedeno P, Pingaron JM. Development of a tyrosinase biosensor based on gold nanoparticles-modified glassy carbon electrodes: application to the measurement of a bioelectrochemical polyphenols index in wines. Anal Chim Acta. 2005;528:1-8.

6. Taton TA, Mirkin CA, Letsinger RL. Scanometric DNA array detection with nanoparticle probes. Science. 2000;289:17571760.

7. Nam JM, Thaxon CS, Mirkin CA. Nanoparticle-based bio-bar codes for the ultrasensitive detection of proteins. Science. 2003;301:1884-1886.

8. Paciotti GF, Myer L, Weinreich D, Goia D, Pavel N, McLaughlin RE, Tamarkin L. Colloidal gold: a novel nanoparticle vector for tumor directed drug delivery. Drug Delivery. 2004;11:169183.

9. O’Neal DP, Hirsch LR, Halas NJ, Payne JD, West JL. Photothermal tumor ablation in mice using near infrared-absorbing nanoparticles. Cancer Lett. 2004;209:171-176.

10. Loo C, Lowery A, Halas N, West J, Drezek R. Immunotargeted nanoshells for integrated cancer imaging and therapy. Nano Lett. 2005;5:709-711.

11. Kim D, Park S, Lee JH, Jeong YY and Jon S. Anti-biofouling polymer-coated gold nanoparticles as a contrast agent for in vivo X-ray computed tomography imaging. J Am Chem Soc. 2007;129:7661-7665.

12. Hainfeld JF, Slatkin DN, Focella TM, Smilowitz HM. Gold nanoparticles: a new X-ray contrast agent. Brit J Radiol. 2006;79:248-253.

13. Gobin AM, Lee MH, Halas NJ, James WD, Drezek RA, West JL. Near-infrared resonant nanoshells for combined optical imaging and photothermal cancer therapy. Nano Lett. 2007;7:1929-1934.

14. Rosi NL, Mirkin CA. Nanostructures in biodiagnostics. Chem Rev. 2005;105:1547-1562.

15. El-Sayed IH, Huang X, El-Sayed MA. Surface plasmon resonance scattering and absorption of anti-EGFR antibody conjugated gold nanoparticles in cancer diagnostics: applications in oral cancer. Nano Lett. 2005;5:829-834.

16. Wilson R. The use of gold nanoparticles in diagnostics and detection. Chem Soc Rev. 2008;37:2028-2045.

17. Alivisatos AP. Perspectives on the physical chemistry of semiconductor nanocrystals. J Phys Chem. 1996;100:13226-13239.

18. Jin R, Cao Y, Mirkin CA, Kelly KL, Schatz GC, Zheng JG. Photoinduced conversion of silver nanospheres to nanoprisms. Science. 2001;294:1901-1903.

19. Daniel M-C, Astruc D. Gold nanoparticles: assembly, supramolecular chemistry, quantum-size-related properties, and applications toward biology, catalysis, and nanotechnology. Chem Rev. 2004;104:293-234.

20. Burda C, Chen X, Narayanan R, El-Sayed MA. Chemistry and properties of nanocrystals of different shapes. Chem Rev. 2005; 105:1025-1102.

21. Thakkar KN, Mhatre SS, Parikh RY. Biological synthesis of metallic nanoparticles. Nanomed Nanotechnol Biol Med. 2010;6:257-262.

22. Reddy BVS, Ramesh S, Ashok Kumar A, Wani SP, Ortiz R, Ceballos H, Sreedevi TK. Bio-fuel crops research for energy security and rural development in developing countries. Bioenergy Res. 2008; 1:248-258.

23. Reddy BVS, Ramesh S, Sanjana Reddy P, Ramaiah B, Salimath PM, Rajasekhar K. Sweet Sorghum - a potential alternate raw material for bio-ethanol and bio-energy. Int Sorghum Millets Newsletter. 2005;46:79-86.

24. Philip D. Honey mediated green synthesis of gold nanoparticles. Spectrochim Acta A. 2009;73:650-653.

25. Kumar CG, Fatima A, Rao PS, Reddy BVS, Rathore A, Rao RN, Khalid S, Ashok Kumar A, Kamal A. Characterization of improved sweet Sorghum genotypes for biochemical parameters, sugar yield and its attributes at different phenological stages. Sugar Tech. 2010;12:322-328.

26. Lazarides AA, Schatz GC. DNA-linked metal nanosphere materials: structural basis for the optical properties. J Phys Chem B. 2000;104:460-467.

27. Aryal S. Remant Bahadur KC, Dharmaraj N, Bhattarai N, Kim $\mathrm{CH}$, Kim HY. Spectroscopic identification of S-Au interaction in cysteine capped gold nanoparticles. Spectrochim Acta A. 2006;63:160-163.

28. Kelly KL, Coronado E, Zhao LL, Schatz GC. The optical properties of metal nanoparticles: the influence of size, shape, and dielectric environment. J Phys Chem B. 2003;107:668-677.

29. Panigrahi S, Kundu S, Ghosh SK, Nath S, Pal T. General method for synthesis of metal nanoparticles. J Nanopart Res. 2004;6:411-414.

30. Ibrahim M, Alaam M, El-Haes H, Jalbout AF, de Leon A. Analysis of the structure and vibrational spectra of glucose and fructose. Ecl Quím Sao Paulo. 2006;31:15-21.

31. Liao $\mathrm{H}$, Wen $\mathrm{W}$, Wong GKL. Photoluminescence from $\mathrm{Au}$ nanoparticles embedded in Au: oxide composite films. $J$ Opt Soc Am B. 2006;23:2518-2521.

32. Barrientos AG, De la Fuente JM, Rojas TC, Fernández A, Penadés S. Gold glyconanoparticles: synthetic polyvalent ligands mimicking glycocalyx-like surfaces as tools for glycobiological studies. Chem Eur J. 2003;9:1909-1921.

33. De la Fuente JM, Barrientos AG, Rojas TC, Rojo J, Cañada J, Fernández A, Penadés S. Gold glyconanoparticles as water-soluble polyvalent models to study carbohydrate interactions. Angew Chem Int Ed. 2001;40:2257-2261.

34. De Paz JL, Ojeda R, Barrientos AG, Penadés S, Martín-Lomas M. Synthesis of a Lex neoglycoconjugate and Ley-functionalized gold glyconanoparticles. Tetrahedron: Asymmetry. 2005;16:149-158.

35. Kumar CG, Mamidyala SK, Das B, Sridhar B, Devi, GS, Karuna MSL. Synthesis of biosurfactant-based silver nanoparticles with purified rhamnolipids isolated from Pseudomonas aeruginosa BS-161R. J Microbiol Biotechnol. 2010;20:1061-1068.

36. De la Fuente JM, Penadés S. Glyco-quantum dots: a new luminescent system with multivalent carbohydrate display. Tetrahedron: Asymmetry. 2005;16:387-391.

37. De la Fuente JM, Alcántara D, Eaton P, Crespo P, Rojas TC, Fernández A, Hernando A, Penadés S. Gold and gold-iron oxide magnetic glyconanoparticles: synthesis, characterization and magnetic properties. J Phys Chem B. 2006;110:13021-13028.

38. De la Fuente JM, Penadés S. Glyconanoparticles: types, synthesis and applications in glycoscience, biomedicine and material science. Biochim Biophys Acta. 2006;1760:636-651.

39. Minh DDL, Chang C, Trylska J, Tozzini V, McCammon JA. The influence of macromolecular crowding on HIV-1 protease internal dynamics. J Am Chem Soc. 2006;128:6006-6007.

Manuscript received Nov. 25, 2010, and revision received Apr. 15, 2011. 